\title{
Pratisyen Diş Hekimi, Çene Cerrahı veya Endodontistin Koyduğu ve Çene Cerrahı ile Endodontistin Multidisipliner Olarak Koyduğu Apikal Cerrahi Endikasyonlarının Retrospektif Olarak Incelenmesi
}

\author{
Fatma Gülfeşan Çanakçi(0000-0001-7553-7062) ${ }^{\alpha}$, Burhan Can Çanakçi(0000-0001-8872-5513) ${ }^{\beta}$
}

Selcuk Dent J, 2021; 8: 744-749 (Doi: 10.15311/selcukdentj.803746)

Başvuru Tarihi: 01 Ekim 2020 Yayına Kabul Tarihi: 12 Kasım 2020

öz

Pratisyen Diş Hekimi, Çene Cerrahı veya Endodontistin Koyduğu ve Çene Cerrahı ile Endodontistin Multidisipliner Olarak Koyduğu Apikal Cerrahi Endikasyonlarının Retrospektif Olarak İncelenmesi

Amaç: Apikal cerrahi diş kaynaklı enfeksiyonların tedavisi için çene cerrahisi uzmanları ve endodontistler tarafından yapılan bir cerrahi uygulamadır. Bu çalışmada farklı dallardaki diş hekimlerinin koydukları apikal cerrahi endikasyonu ile kurumumuzda çene cerrahisi uzmanı ve endodontistin birlikte koyduğu endikasyonların ile karşılaştıııması amaçlanmıştır.

Gereç ve Yöntemler: 2014 - 2020 yılları arasında Trakya Üniversitesi, Diş Hekimliği Fakültesine apikal cerrahi için yönlendirilen 590 sayıda hasta, sevk eden diş hekiminin uzmanlık durumu, sevk öncesi dişlere uygulanan tedavi, sevk öncesi/sırasında semptom olup olmaması, ilgili dişlerde mevcut olan periapikal lezyon boyutu ve ilgili dişler için kurumumuzda koyulan endikasyon açısından değerlendirilmiştir.

Bulgular: Hastalara kurumumuzda apikal cerrahi endikasyonu koyulma oranı \% 8 olarak tespit edilmiştir. Endodontist tarafından sevk edilen hastaların \% 33, çene cerrahı tarafından sevk edilenlerin $\% 11$ ve pratisyen diş hekimi tarafından sevk edilenlerin ise \% 2'sine kurumumuzda apikal cerrahi endikasyonu koyulmuştur $(P<0,05)$. Hastaların \% 64'üne kurumumuza başvurmadan önce sevk eden hekim tarafından kök kanal tedavisi uygulanmamıştır. Kök ucunda radyolojik olarak lezyon olmayan dişlerin \% 11'ine, bir dişi kapsayan lezyon olan dişlerin \% 3'üne, bir - üç dişi kapsayan lezyon olan dişlerin \%8'ine ve üç dişten büyük lezyonu olan dișlerin \% 9'una kurumumuzda apikal cerrahi endikasyonu koyulmuştur.

Sonuç: Bu çalışmanın sonuçlarına göre apikal cerrahi endikasyonu açısından pratisyen diş hekimi, cerrahi uzmanı ve endodontist arasında farklı görüşler mevcuttur. Ayrıca endodontist ve çene cerrahının multidisipliner değerlendirme ile koydukları endikasyon oranı daha düşüktür.

\section{ANAHTAR KELIMELER}

Apikal cerrahi, Çene cerrahı, Endodontist, Pratisyen diş hekimi

Endodontik tedavi bakteri istilasına uğramış kök kanalının kemo-mekanik olarak temizlenmesini ve kök kanalı kaynaklı apikal periodontitisin iyileşmesini amaçlar. Kök kanal tedavisinin (KKT) yüksek başarı oranına rağmen kök kanalının özellikle apikal üçlüsünün yeterince dezenfekte edilememesi, kök kanalındaki inatçı mikroorganizmalar, kök dışı biyofilm ve mikroorganizmalar, kök ucundaki kistik değişimler,

\section{ABSTRACT}

Retrospective Examination of Apical Surgery Indications Presented by General Practitioner, Maxillofacial Surgeon or Endodontist and Multidisciplinary Determined by Maxillofacial Surgeon and Endodontist

Background: Apical surgery is a surgical operation performed by maxillo-facial surgeons and endodontists for the treatment of odontogenic infections. The aim of this study is to compare the indications of apical surgery by dentists in different branches with the indications by the dental surgeon and endodontist in our institution.

Methods: 590 patients who were referred to Trakya University, Faculty of Dentistry between 2014 - 2020 for apical surgery were participated. The evaluated criterias are the expertise of the referring dentist, the treatment applied to the teeth before the referral, the presence of symptoms before / during the referral, the size of the periapical lesion present in the relevant teeth and the indication in our institution.

Results: The rate of $A C$ indication for patients in our institution was determined to be $\% 8$. The apical surgary rate in our institution was $33 \%$ of the patients referred by the endodontist, $11 \%$ by the maxillofacial surgeon and $2 \%$ by the general practitioner dentist $(P<0.05)$. Root canal treatment was not applied to $64 \%$ of patients before referral. Apical surgery indication rates in our institution were $11 \%$ for radiologically no lesions at the root tip, 3\% for lesion containing one tooth, $8 \%$ for lesion containing one - three teeth, and $9 \%$ for lesions larger than three teeth.

Conclusion: According to the results of this study, there are different opinions between the general practitioner, the surgeon and the endodontist in terms of the indication for apical surgery. In addition, the rate of indication that the endodontist and maxillofacial surgeon has established with multidisciplinary evaluation is lower.

\section{KEYWORDS}

Apical surgery, General practitioner, Endodontist, Maxillofacial surgeon

tedavinin ideal olarak yapılamaması gibi sebeplerden dolayı apikal periodontitis tekrarlayabilir ve ilerleyebilir. ${ }^{1}$

Başarısız KKT'nin çözümü olarak öncelikle tekrarlayan kök kanal tedavisi (RT) önerilmektedir. Bununla birlikte RT'nin de başarısız olması ya da uygulanamaması durumlarda apikal cerrahi (AC) yada bilinçli replantasyon gibi tedaviler

\footnotetext{
${ }^{\alpha}$ Trakya Üniversitesi Diş Hekimliği Fakültesi Ağız Diş ve Çene Cerrahisi AD, Edirne, Türkiye
}

$\beta$ Trakya Üniversitesi Diş Hekimliği Fakültesi Endodonti AD, Edirne, Türkiye 
önerilmektedir. ${ }^{2}$ AC endikasyonları uygun yapılmış kök kanal tedavisine rağmen devam eden periradiküler inflamasyon, iyileşmeyen kök ucu lezyonu, tekrarlayan/geçmeyen semptomlar, periapikal dokulardan biyopsi gereksinimi gibi biyolojik nedenler, kron ve/veya post varlığı, kırık kanal aleti bulunması, mevcut kök kanal dolgu maddesinin uzaklaştırılamaması, aşırı eğim gibi anatomik zorluklar ve ortograd tedavinin mümkün olmadığı durumlar gibi teknik nedenler olarak sayılabilir. ${ }^{3} \mathrm{Bu}$ tür dişlerde tedavi seçimi birçok faktörden etkilenmektedir. Dişin ağızdaki yeri, kronun restore edilebilirliği, daha önce yapılmış kök kanal tedavisinin kalitesi, kemik kalitesi, periodontal destek, kök/kron oranı, klinik tecrübe, hasta beklentileri, estetik/sosyal/işlevsel hasta talepleri, sistemik durum gibi durumlar tedavi türünü belirlemede rol oynar. KKT ya da RT sonrası başarısızlık görülen dişlerde tedavi seçenekleri başarısızlığın sebebi ile hekimin teorik/pratik bilgisine ve becerisine göre farklılık gösterebilmektedir. ${ }^{4}$ Ayrıca dental tedavilerde tedavi kararlarının genel diş hekimleri ve uzman diş hekimleri arasında farklılık gösterebildiği bildirilmiştir. ${ }^{5}$ Hekim kararı ile birlikte estetik, psikolojik ve ekonomik sebepler ile hastanın tercihleri de endikasyon aşamasında önemli rol oynamaktadır.

Çalışmamızın amacı dış kurumlardan AC için kurumumuza sevk edilen hastalara koyulan endikasyonlar ile kurumumuzda çene cerrahı ve endodontistin ortak olarak koyduğu endikasyonların uyumunu incelemektir.

\section{GEREÇ VE YÖNTEMLER}

Etik onayı alınmış olan (Trakya Üniversitesi, Bilimsel Araştırmalar Etik Kurulu; xxx: 2020/318) bu retrospektif çalışamaya Ocak 2014 -Ocak 2020 arasında Trakya Üniversitesi, Diş Hekimliği Fakültesine başvuran ve başka bir sağlık kuruluşundan AC endikasyonu ile yönlendirilmiş 590 adet hasta dahil edilmiştir. Kurumumuzun işleyişi dâhilinde $A C$ endikasyonu ile sevk edilen bu hastalar, sevk edildikleri tarihlerde Oral Diagnoz ve Radyoloji Bölümünde muayene edildikten sonra tedavi seçeneklerinin değerlendirilesi için ağız, diş ve çene cerrahisi uzmanı ve endodonti uzmanına konsülte edilmiş, ilgili hekimler tarafından klinik ve radyolojik olarak tarafından tekrar muayene edilmiş ve endikasyon konusunda ortak bir karara varılmıştır.

Çalışma dâhilinde hastaların anamnez kayıtları, tedavi planları ve uygulanan tedaviler analiz edilmiştir. Hasta kayıtları incelenerek değerlendirilen kriterler şu şekildedir;

1. Cinsiyet

2. Yaş

3. Öğrenim durumu

4. Aylık gelir

5. AC için sevk eden diş hekiminin uzmanlık durumu

6. Sevk öncesi dişlere tedavi uygulanıp uygulanmadığı

7. Sevk öncesi/sırasında semptom olup olmaması

8. İlgili dişlerde mevcut olan periapikal lezyon durumu/boyutu

9. İlgili dişler için kurumumuzda koyulan endikasyon

Veriler SPSS (ver. 22.0; SPSS Inc., Şikago, IL, ABD) yazılımı kullanılarak incelenmiştir. Veriler yüzdesel olarak değerlendirilmiştir. Karşılaştırmalarda Ki-kare testi kullanılmıştır $(\mathrm{P}<0,05)$.

\section{BULGULAR}

Çalışmamızda değerlendirilen hastaların demografik dağılım özellikleri Tablo 1'de görülmektedir.

Tablo 1.

\section{Antropometrik yumuşak dokuları ve tanımlamaları}

\begin{tabular}{|c|c|c|c|c|}
\hline & & n & $\%$ & \\
\hline \multirow{2}{*}{ Cinsiyet } & Kadın & 246 & 42 & \multirow{2}{*}{$P>0,05$} \\
\hline & Erkek & 344 & 58 & \\
\hline \multirow{4}{*}{$\begin{array}{l}\text { Öğrenim } \\
\text { Durumu }\end{array}$} & $\begin{array}{l}\text { Okur-yazar } \\
\text { olmayan }\end{array}$ & 1 & $<1$ & \multirow{4}{*}{$P<0.05$} \\
\hline & İlköğretim & 68 & 12 & \\
\hline & Lise & 245 & 42 & \\
\hline & Üniversite & 276 & 46 & \\
\hline \multirow{4}{*}{ Gelir Durumu } & $<2000 \mathrm{TL}$ & 185 & 31 & \multirow{4}{*}{$P>0,05$} \\
\hline & $2000-5000 \mathrm{TL}$ & 189 & 32 & \\
\hline & $\begin{array}{l}5000-10000 \\
T L\end{array}$ & 156 & 26 & \\
\hline & $>10000 \mathrm{TL}$ & 60 & 10 & \\
\hline
\end{tabular}

Çalışmamızın sonuçlarına göre hastaların \% 58'i erkek, \% 42'si kadındır $(P>0,05)$. Hastaların en sık olarak 18-40 yaş grubunda olduğu görülmüştür $(\% 67, \mathrm{P}<0,05)$.

Hastaların kurumumuza başvurmadan önce ilgili dişe bir tedavi uygulanıp, uygulanmadığı, semptom durumu, kök ucundaki lezyon varlığı ve boyutu, sevk eden diş hekiminin uzmanlık durumu ve kurumumuzda koyulan AC endikasyon dağılımı Tablo 2'de görülmektedir. Hastalara kurumumuzda AC endikasyonu koyulma oranı \%8 olarak tespit edilmiştir $(P<0,05)$. Hastaların \% 67'si pratisyen diş hekimi, \% 18'i çene cerrahı ve \% 15'i endodontist tarafından sevk edilmiştir $(P<0,05)$. Endodontist tarafından sevk edilen hastaların \% 33, çene cerrahı tarafından sevk edilenlerin \% 11 ve pratisyen diş hekimi tarafından sevk edilenlerin ise \% 2'sine kurumumuzda $A C$ endikasyonu koyulmuştur $(P<0,05)$. Hastaların \% 64'üne kurumumuza başvurmadan önce sevk eden hekim tarafından KKT uygulanmamıştır. Tedavi uygulanmadan sevk edilen hastaların endodontistlerin yönlendirdiklerinin $\% 19$, çene cerrahlarının yönlendirdiklerinin \% 4 ve pratisyen hekimlerin yönlendirdiklerinin \% 3'üne AC endikasyonu koyulmuştur. Tedavi uygulandıktan sonra sevk edilenlerin hastaların ise endodontistlerin yönlendirdiklerinin \% 48 'ine, çene cerrahlarının yönlendirdiklerinin \% 20'sine ve pratisyen hekimlerin yönlendirdiklerinin \%2'sine AC endikasyonu koyulmuştur. 
Tablo 2

Apikal cerrahi endikasyonu ile sevk edilen hastaların sevk eden doktor, semptom durumu, sevk öncesi işlem uygulanma durumu ve kurumumuzda koyulan endikasyon sayıları

\begin{tabular}{|c|c|c|c|c|c|c|c|c|}
\hline & & & Lezyon & Toplam & & & & \\
\hline & & & & \multicolumn{5}{|c|}{ Sevk eden hekim } \\
\hline & & & & & Endodontist & $\begin{array}{l}\text { Çene } \\
\text { cerrahı }\end{array}$ & Pratisyen & \\
\hline \multirow{10}{*}{$\begin{array}{c}\mathrm{KKT} \\
(-)\end{array}$} & \multirow{5}{*}{$\begin{array}{l}\text { Semptom } \\
(+)\end{array}$} & & & $\begin{array}{c}224 \text { * } \\
17\end{array}$ & $38 * 9$ & $37 * 3$ & $149 * 5$ & Toplam \\
\hline & & & $(-)$ & $51 * 10$ & $11 * 6$ & 0 & $40 * 4$ & \\
\hline & & & 1 diş & $41 * 0$ & $2 * 0$ & 0 & $39 * 0$ & \\
\hline & & & $1-3$ diş & $48 * 2$ & $7 * 1$ & $13 * 1$ & $28 * 0$ & \\
\hline & & & $>3$ & $84 * 4$ & 18 *2 & $24 * 2$ & $42 * 1$ & \\
\hline & \multirow{5}{*}{$\begin{array}{c}\text { Semptom } \\
(-)\end{array}$} & & & $151 * 3$ & $20 * 2$ & $30 * 1$ & $101 * 0$ & Toplam \\
\hline & & & $(-)$ & $23 * 1$ & $4 * 1$ & 0 & $19 * 0$ & \\
\hline & & & 1 diş & $31 * 0$ & 0 & 0 & $31 * 0$ & \\
\hline & & & $1-3$ diş & $39 * 0$ & $4 * 0$ & $11 * 0$ & $24 * 0$ & \\
\hline & & & $>3$ & $58 * 2$ & $12 * 1$ & $19 * 1$ & $27 * 0$ & \\
\hline \multirow{16}{*}{$\begin{array}{l}\text { KKT } \\
(+)\end{array}$} & \multirow{5}{*}{$\begin{array}{c}\text { KKT } \\
\text { sonrası } \\
\text { semptom } \\
(-)\end{array}$} & & & $40 * 3$ & $7 * 3$ & 0 & $33 * 0$ & Toplam \\
\hline & & & $(-)$ & $2 * 0$ & 0 & 0 & $2 * 0$ & \\
\hline & & & 1 diş & $18 * 0$ & 0 & 0 & $18 * 0$ & \\
\hline & & & $1-3$ diş & $14 * 1$ & $4 * 1$ & 0 & $10 * 0$ & \\
\hline & & & $>3$ & $6 * 0$ & $3 * 2$ & 0 & $3 * 0$ & \\
\hline & \multirow{11}{*}{$\begin{array}{c}\text { KKT } \\
\text { sonrası } \\
\text { semptom } \\
(+)\end{array}$} & & & $46 * 13$ & $15 * 9$ & $12 * 4$ & $19 * 0$ & Toplam \\
\hline & & & $(-)$ & $3 * 0$ & 0 & 0 & $3 * 0$ & \\
\hline & & \multirow{3}{*}{$\begin{array}{l}\text { RT } \\
(+)\end{array}$} & 1 diş & $17 * 3$ & $7 * 3$ & 0 & $10 * 0$ & \\
\hline & & & $1-3$ diş & $9 * 2$ & $2 * 1$ & $3 * 1$ & $4 * 0$ & \\
\hline & & & $>3$ & $17 * 8$ & $6 * 5$ & $9 * 3$ & $2 * 0$ & \\
\hline & & \multirow{6}{*}{$\begin{array}{l}\text { RT } \\
(-)\end{array}$} & & $\begin{array}{c}129 * \\
13\end{array}$ & $9 * 6$ & $29 * 4$ & $91 * 3$ & Toplam \\
\hline & & & $(-)$ & $25 * 0$ & 0 & 0 & $25 * 0$ & \\
\hline & & & 1 diş & $19 * 1$ & $2 * 1$ & $4 * 0$ & $13 * 0$ & \\
\hline & & & $1-3$ diş & $58 * 8$ & 2 * 2 & $17 * 3$ & $39 * 3$ & \\
\hline & & & $>3$ & $27 * 4$ & $5 * 3$ & $8 * 1$ & $14 * 0$ & \\
\hline & & & & & $89 * 29$ & $\begin{array}{c}108 \text { * } \\
12\end{array}$ & 393 * 8 & Toplam \\
\hline
\end{tabular}

Kök ucu lezyon varlığı ve boyutu, sevk eden hekim ve kurumumuzda koyulan endikasyon yüzdeleri Tablo 3'deki gibidir.

\section{Tablo 3.}

Kök ucu lezyon durumu, hekim tipleri ve endikasyon oranları

\begin{tabular}{|c|c|c|c|c|c|c|c|}
\hline & \multicolumn{2}{|c|}{ Endodontist } & \multicolumn{2}{|c|}{ Çene Cerrahı } & \multicolumn{2}{|c|}{ Pratisyen } \\
\hline & & $\begin{array}{l}\text { Sevk } \\
\text { sayısı }\end{array}$ & $\begin{array}{l}\text { Kurumumuz } \\
\text { AC oranı }(\%)\end{array}$ & $\begin{array}{l}\text { Sevk } \\
\text { sayisı }\end{array}$ & $\begin{array}{l}\text { Kurumumuz AC } \\
\text { oranı (\%) }\end{array}$ & $\begin{array}{l}\text { Sevk } \\
\text { sayisı }\end{array}$ & $\begin{array}{l}\text { Kurumumuz } \\
\text { AC oranı }(\%)\end{array}$ \\
\hline \multirow{4}{*}{ 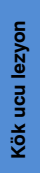 } & $(-)$ & 15 & 46 & 0 & 0 & 89 & 4 \\
\hline & 1 diş & 11 & 36 & 4 & 0 & 111 & 0 \\
\hline & $\begin{array}{l}1-3 \\
\text { diş }\end{array}$ & 19 & 42 & 44 & 16 & 122 & 3 \\
\hline & $>3$ diş & 44 & 40 & 60 & 12 & 88 & 0 \\
\hline
\end{tabular}

Kök ucunda radyolojik olarak lezyon olmayan dişlerin (104 adet, \% 18) \% 11'ine, bir dişi kapsayan lezyon olan dişlerin (126 adet, \% 28) \% 3'üne, bir - üç dişi kapsayan lezyon olan dişlerin (168 adet, \% 28) \% 8'ine ve üç dişten büyük lezyonu olan dişlerin (192 adet, \% 33) \%9'una kurumumuzda $A C$ endikasyonu koyulmuştur $(P<0,05)$. Apikal cerrahi için endodontistin sevk ettiği hastaların çoğunun 3 dişten fazla lezyon içerdiği görülmüştür $(P<0,05)$. Çene cerrahının ise en çok 1-3 diş ve 3 dişten fazla lezyon içeren hastaları gönderdiği tespit edilmiştir $(P<0,05)$.

\section{TARTIŞMA}

Bu çalışmanın sonuçlarına göre pratisyen diş hekimleri, endodontistler ve çene cerrahları arasında $A C$ endikasyon değerlendirmeleri arasında belirgin farklııklar vardır. Genel olarak endodontistlerin daha konservatif kararlar verdikleri, pratisyen diş hekimlerinin ise KKT öncesinde bile AC endikasyonu ile hastaları üniversite hastanesine gönderdikleri görülmüştür. Ayrıca çalışmanın sonucu olarak AC endikasyonunun endodontist ve çene cerrahının birlikte değerlendirerek koyulması ile çok daha konservatif yaklaşımlar elde edildiği söylenebilir.

Kurumumuzda üniversite hastanesi olmanın avantajı ile rutin uygulama olarak AC endikasyon/tedavi aşamasında multidisipliner yaklaşım uygulanmaktadır. Kök kanal tedavi, kök kanal tedavisi yenileme, apikal cerrahi, bilinçli replantasyon, çekim ve implant tedavisi karar süreci çok fazla faktör açısından değerlendirilmesi gereken bir süreçtir. Farklı bilim disiplinlerinin farklı bakış açıları ile değerlendirmesi sonucu endikasyon aşamasında farklılıklar ortaya çıkabilir. Farklı bilim dallarının farklı değerlendirme kriterleri sonucunda hastanın talep ve beklentileri çok daha başarılı şekilde karşılanabilir.

Bu çalışmanın sonuçlarına göre; pratisyen diş hekimleri, endodontistler ve çene cerrahları arasında AC endikasyon değerlendirmeleri arasında belirgin farklııklar vardır. Genel olarak endodontistlerin daha konservatif kararlar verdikleri, pratisyen diş hekimlerinin ise KKT öncesinde bile AC endikasyonu ile hastaları üniversite hastanesine gönderdikleri görülmüştür. Ayrıca çalışmanın sonucu olarak AC endikasyonunun endodontist ve çene cerrahının birlikte değerlendirerek koyulması ile çok daha konservatif yaklaşımlar elde edildiği söylenebilir.

Klinik tedavi kararı bilgi, tecrübe ve hasta kararını içeren karışık bir süreçtir. ${ }^{4}$ Daha önceki çalışmalarda diş hekimleri arasında uzmanlık varlığı/yokluğu ve uzmanlık dalının tedavi kararları üzerinde etkili olduğu 
bildirilmiştir. ${ }^{6,7}$ Bizim çalışmamızdaki pratisyen hekim kararlarındaki yüksek farklıı değerleri endikasyon/tedavi aşamalarındaki bilgi, tecrübe ve kişisel yorum/tercih farklarından kaynaklanıyor olabilir. Ayrıca pratisyen diş hekimlerinin karar süreçlerinde risk analizinden ziyade kişisel önem değerleri ve tecrübeye bağlı kararların önemli yer tuttuğu bildirilmiștir. ${ }^{5,8}$ Farklı zorluk seviyelerinde hazırlanmış simülasyon dental teşhis problemleri içeren çalışmalarda en zor soruların pratisyenler tarafından ya çok kolay yada kolay olarak yorumlanması ${ }^{4}$ ve bu sorularda uzman diş hekimlerine göre belirgin yüksek oranda hata yapılmış olması bu duruma bir örnektir. ${ }^{9}$ Farklı eğitim ekollerine bağlı olarak da endikasyonlarda farklııklar görülebilir. Bölgesel olarak hastalarının tercihlerinin değişmesi durumu da hekimin endikasyonu üzerinde etkili olabilir.10

Uzman diş hekimleri arasında endikasyon aşamasında belli oranda uyum rapor edilmiştir. ${ }^{12}$ Bununla birlikte endodontistler pratisyenler ve diğer dalların uzmanlarına göre daha konservatif endikasyon kararları vermektedir. ${ }^{8,13}$ Ayrıca prognozu şüpheli dişlerde endodontistlerin teorik bilgilerine ve pratik becerilerine daha fazla güvendikleri söylenebilir. ${ }^{4}$ Endodontist ile çene cerrahı arasındaki endikasyon farklılıkları tedavi planlama aşamasında incelenen faktörlerin farklılığından kaynaklanabilir. Bir çalışmada çene cerrahına AC için gönderilen hastaların \% 55'inin ortograd tedavi değerlendirmeleri için çene cerrahı tarafından endodontiste yönlendirildiği bildirilmiştir. ${ }^{7}$ Ayrıca Von Arx ve ark. pratisyen hekimler tarafından uzmanlara sevk edilen işlemler arasında en sık olanın apikal cerrahi olduğu bildirilmiştir. ${ }^{11}$

Apikal cerrahi endikasyonu için biyolojik faktörler arasında en sık olanı \% 54,1 ile birincil ve/veya tekrarlayan kök kanal tedavisi sonrası semptomların devam etmesi, ${ }^{3}$ nadiren de olsa kistik değişimler, ekstra radiküler enfeksiyonlar ve yabancı cisim reaksiyonlarıdır. ${ }^{14}$ Ayrıca, konservatif ortograd yaklaşım mümkün değil ya da çok riskli ise cerrahi önerilir. ${ }^{6}$ Kök ucu cerrahisinin endikasyonları Avrupa Endodonti Derneği tarafından 2006'da şu şekilde belirlenmiştir; Apikal periodontitisin radyolojik bulgularının olması ve/veya kanalın tedavi edilmesini güçleştiren etkenle ilişkili olarak semptomların devam etmesi, klinik ve radyolojik olarak apikal periodontitis bulguları veren taşan materyal ve/veya uzun zamandır devam eden semptomlar, RT'nin mümkün olmadığı durumda KKT'yi takiben ısrarcı ya da yeni gelişen hastalık durumu ve pulpa kavitesi içinden tedavi edilmesi mümkün olmayan pulpa odası tabanının ya da kökün perforasyonudur. ${ }^{15}$ Bununla birlikte endodontik başarısızlıklıkların büyük bir kısmının kemo mekanik şekillendirme ve dolumdaki yetersizliklerin kök kanalındaki mikrobiyal durum ile ilişkili olduğu söylenebilir. ${ }^{7}$ Bu durumunda öncelikli tedavi RT'dir. Kvist ve ark.'a ${ }^{5}$ göre endodontik tedavi başarısızlıklarda pratisyenlerin sadece \% 6'sı, Taha ve ark'a $^{12}$ göre ise endodontistlerin büyük kısmı RT tercih etmektedir. Ayrıca kök kanalının dolgu kalitesinin kötü olması hekimleri tekrarlayan tedaviyi düşündüren en önemli bulgulardandır. ${ }^{16}$ Epidemiyolojik çalışmalara göre uygun olmayan dolumların oranı \% 60 , bunlarında arasındaki tekrarlayan apikal preiodontitis oranı \% 40 'dır. ${ }^{19}$ Bununla birlikte radyolojik ve klinik olarak uygun yapılmış kök kanal tedavilerinde bile kalıcı/inatçı apikal periodontitis bulguları olabilir. ${ }^{17} \mathrm{Bu}$ bulguların en doğru olarak endodontistler tarafından değerlendirildiği bildirilmiştir. ${ }^{16}$ Birgas ve ark. aynı hastalarda RT oranlarının endodontistlerde \% 96, protez uzmanlarında $\% 36$, çene cerrahlarında $\% 31$, periodontoloji uzmanlarıda $\% 24$ ve pratisyenlerde \% 48 olarak bildirmiștir. ${ }^{4}$

Periapikal doku sağlığı klinik bulgular ve radyolojik değerlendirme ile tespit edilir. Kvist18 periapikal lezyon varlığında tercih edilen tedavinin hekimler arasındaki farklılıklarını açıklamak için "Praxis Konsepti"ni tanımlamıştır; buna göre periapikal doku sağlığını/hastalığını farklı hekimler farklı süreçler olarak yorumlanır. Radyografiler ile periapikal lezyon varlığı ve boyutu değerlendirilirken, iyileşme durumu semptom ve hastalığın bulguları ile belirlenebilir. Buna göre farklı radyolojik durumlarda farklı iyileşme seviyeleri hekimler tarafından bilgi ve tecrübeye göre farklı yorumlanabilir. ${ }^{18} \mathrm{Bu}$ konsepte göre daha büyük radyolüsensiler hekimler tarafından daha tehlikeli olarak yorumlanabilmektedir. Lezyon boyutu arttıkça daha dirençli mikrobiyal biyofilm oluşma intimali olmasına rağmen ${ }^{2}$ lezyon boyutunun periapikal lezyon iyileşmesi üzerine doğrudan etkisi yoktur. ${ }^{19}$ Radyolojik değerlendirme göz önüne alındığında pratisyen - çene cerrahı - endodontist arasında belirgin yorum farklııkları bildirilmiştir. ${ }^{20-22}$ Geleneksel olarak KKT yapılmış dişlerde periapikal lezyon varlı̆ı̆ RT ya da AC için sebeptir ${ }^{15}$ ama asemptomatik vakalarda takip edilmesi önerilir. ${ }^{12}$ Bununla birlikte, farklı hekimler lezyon iyileşme süreçleri hakkında potansiyel iyileşme gücü, farklı tedavileri yarar/zararları ve maliyete göre farklı yorumlar yapabilir. ${ }^{16}$ Semptom varlığı - yokluğu ile endodontik başarı arasındaki ilișki de hekimler tarafından farklı yorumlanabilmektedir. ${ }^{18}$ Özellikle asemptomatik ve lezyonlu dişlerde genel olarak endodonti uzmanları pratisyen ve çene cerrahlarına göre daha fazla takip kararı vermektedir. ${ }^{12,23}$

Prognozu şüpheli dişlerin tedavisinde KKT, RT ve AC'nin diğer bir alternatifi de implant tedavisidir. Bu tedavi seçeneklerinin yüksek başarısı hangisini seçme konusunda tartışmalara sebep olmaktadır. Kısa süreçlerde (2-3 yıl) RT'nin AC'ye göre daha başarısız olduğu, uzun dönemde ise (4-6 yıl) daha başarıı olduğu bildirilmiştir. ${ }^{24}$ Tek diş implant tedavisi ve KKT uygulanmış dişlerin başarı oranları benzerdir. ${ }^{29}$ Bununla birlikte AC'nin daha başarılı olduğunu bildiren endodontik literatür mevcut iken, cerrahi literatür tek diş implantın daha başarıı olduğunu bildirmektedir. ${ }^{16}$ Pratisyenler ve çene cerrahlarının KKT gereksinimi olan 
dişlerde implant tercihinin \% 9,5, RT gerektiren dişlerde ise \% 25 oranında olduğu bildirilmiştir. ${ }^{16}$ Benzer hasta gruplarında endodontistlerin RT tercihleri \%96, protez uzmanlarının \% 36, çene cerrahlarının \%31, periodontoloji uzmanlarının $\% 24$ ve pratisyenlerin $\% 48$ olduğu rapor edilmiştir. ${ }^{4}$ Özetle endodontistler daha konservatif tedaviler tercih ederken pratisyen ve diğer uzmanlık dallarındaki hekimler daha radikal planlamalar yaparak çekim-implant sıklıkla tercih etmektedir. ${ }^{16}$ Ayrıca yeni mezun hekimlerin eski hekimlere göre şüpheli prognozu olan dişlerde daha fazla çekim-implant tercih ettiği bildirilmiştir. ${ }^{16} \mathrm{Bu}$ durum muhtemel mezuniyet sonrası fazlaca olan implant eğitimleri/reklamları ve maddi kaygılar sebepliolabilir. Pratisyen diş hekimlerinde RT ve AC yerine çekim-implant ya da diğer protetik çözümlerin daha sık tercih edilmesinin diğer sebepleri de RT ve AC işlemlerine teorik ve pratik olarak hâkim olunmaması ve klinik tecrübenin daha ziyade protetik çözümler yönünde olması olabilir. ${ }^{23} \mathrm{AC}$ başarı oranı yüksek bir tedavi olsa bile gelişen teknoloji ile teknik hassasiyeti de artmış olan bir tedavidir. Mikro endodontik cerrahi, mikroskop-loop kullanımı, ultrasonik aletler, mikro el aletleri vb. kullanımı için ilave eğitimin gerekli olması pratisyen hekimleri diğer tedavi seçeneklerine itiyor olabilir. Ayrıca pratisyen hekimlerin AC endikasyonunu çok fazla koymalarına rağmen, muhtemel tecrübe eksikliği ve maddi kaygılar sebebi ile endodontist ve çene cerrahlarına göre çok daha az yapmakta,12 sıklıkla benzer dişlere çekim kararı vermektedirler. ${ }^{25}$

AC tercih noktasında dikkat çeken farklı bir durumda da pratisyen hekimlerin $A C$ endikasyonu koydukları dişleri endodontiste değil genellikle çene cerrahına sevk etmeleridir. ${ }^{26}$ Abramovitz ve ark. AC için çene cerrahına yönlendirilen hastaların \% 55'inin ilave değerlendirme talebi ile endodontiste

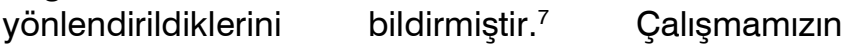
sonuçlarına göre AC endikasyonunun çene cerrahı ile birlikte endodontistin karar vermesinin önemli olduğunu söyleyebilir. AC için öncelikle dişin restore edilebilir olduğu, ortograd yöntemle tedavi önceliği, tekrarlayan tedavi gereksinimi, kemik durumu-kaybı, periapikal patoloji tipi vs gibi değerlendirilmesi gereken durumlar multidisipliner görüşler gerektirir. Ayrıca Von Arx ve ark. pratisyen hekimler tarafindan AC yada çekim kararı ile yönlendirilmiş ve çene cerrahı ile endodontist tarafindan muayene edilen hastalarda \% 25,8 oranında yanlış çekim endikasyonu konulduğunu bildirmiştir. ${ }^{11}$

\section{SONUÇ}

1. AC endikasyonu en sık pratisyen hekimler tarafından koyulurken, endikasyon uyumu daha da düşüktür.

2. Çalışmamızın sonuçlarına göre pratisyen hekimlerin AC endikasyonu koyduğu dişlerin <\%10'una kurumumuzda çene cerrahı - endodontist tarafından AC endikasyonu koyulmuştur.

3. Endikasyon aşamasında farklı hekimlerin ve uzmanlık dallarının farklı görüşleri olmaktadır. Hasta için en yararlı ve başarılı tedavi tercihi için çene cerrahı ile endodontist, hatta protez uzmanı birlikte karar verir ise multidisipliner yaklaşım sağlanabilir. 


\section{KAYNAKLAR}

1. Sjögren U, Hägglund B, Sundqvist G, Wing K. Factors affecting the long-term results of endodontic treatment. $J$ Endod. 1990;16(10):498-504.

2. Ricucci D, Siqueira Jr JF. Biofilms and apical periodontitis: study of prevalence and association with clinical and histopathologic findings. $J$ Endod. 2010;36(8):1277-88.

3. El-Swiah J, Walker R. Reasons for apicectomies. A retrospective study. Dent Traumatol. 1996;12(4):185-91.

4. Bigras BR, Johnson BR, BeGole EA, Wenckus CS. Differences in clinical decision making: a comparison between specialists and general dentists. Oral Surg Oral Med Oral Pathol Oral Radiol Endod. 2008;106(1):139-44.

5. Kvist $T$, Heden G, Reit C. Endodontic retreatment strategies used by general dental practitioners. Oral Surg Oral Med Oral Pathol Oral Radiol Endod. 2004;97(4):5027.

6. Beckett $\mathrm{H}$. Impact of a restorative dentistry service on the prescription of apical surgery in a district general hospital. Ann R Coll Surg Engl. 1996;78(4):369.

7. Abramovitz I, Better H, Shacham A, Shlomi B, Metzger Z. Case selection for apical surgery: a retrospective evaluation of associated factors and rational. J Endod. 2002;28(7):527-30.

8. McCaul L, McHugh S, Saunders W. The influence of specialty training and experience on decision making in endodontic diagnosis and treatment planning. Int Endod J. 2001;34(8):594-606.

9. Rawski AA, Brehmer B, Knutsson K, Petersson K, Reit C, Rohlin $M$. The major factors that influence endodontic retreatment decisions. Swed Dent J. 2003;27(1):23-9.

10.Baicker K, Chandra A, Skinner JS, Wennberg JE. Who You Are And Where You Live: How Race And Geography Affect The Treatment Of Medicare Beneficiaries: There is no simple story that explains the regional patterns of racial disparities in health care. Health Aff. 2004;23(Suppl2):VAR-33-VAR-44.

11.von Arx T, Roux E, Bürgin W. Treatment decisions in 330 cases referred for apical surgery. $J$ Endod. 2014;40(2):187-91.

12. Taha NA, Albashaireh ZS, Alfied RG. Endodontic decision making for asymptomatic root-filled teeth with apical periodontitis-A radiographic survey. Aust Endod J. 2019;45(1):40-5.

13.Balto HAG, Al-Madi EM. A comparison of retreatment decisions among general dental practitioners and endodontists. J Dent Educ. 2004;68(8):872-9.

14.Strbac GD, Schnappauf A, Giannis K, Moritz A, Ulm C. Guided Modern Endodontic Surgery: A Novel Approach for Guided Osteotomy and Root Resection. J Endod. 2017(3):496-501.

15. Endodontology ESo. Quality guidelines for endodontic treatment: consensus report of the European Society of Endodontology. Int Endod J. 2006;39(12):921-30.
16. Wenteler G, Sathorn C, Parashos P. Factors influencing root canal retreatment strategies by general practitioners and specialists in A ustralia. Int Endod J. 2015;48(5):417-27.

17. Siqueira Jr JF. Aetiology of root canal treatment failure: why well-treated teeth can fail. Int Endod J. $2001 ; 34(1): 1-10$.

18. Kvist T, Reit C, Esposito M, Mileman P, Bianchi S, Pettersson $\mathrm{K}$, et al. Prescribing endodontic retreatment: towards a theory of dentist behaviour. Int Endod J. 1994;27(6):285-90.

19. Huumonen S, Ørstavik D. Radiographic follow-up of periapical status after endodontic treatment of teeth with and without apical periodontitis. Clin Oral Investig. 2013;17(9):2099-104.

20. Goldman M, Pearson AH, Darzenta N. Endodontic success-who's reading the radiograph? Oral Surg Oral Med Oral Pathol. 1972;33(3):432-7.

21.Saunders M, Gulabivala K, Holt R, Kahan R. Reliability of radiographic observations recorded on a proforma measured using inter-and intraobserver variation: a preliminary study. Int Endod J. 2000;33(3):272-8.

22. Goldman M, Pearson AH, Darzenta N. Reliability of radiographic interpretations. Oral Surg Oral Med Oral Pathol. 1974;38(2):287-93.

23.Dechouniotis G, Petridis XM, Georgopoulou MK. Influence of specialty training and experience on endodontic decision making. J Endod. 2010;36(7):1130-4.

24.Torabinejad M, Corr R, Handysides R, Shabahang $S$. Outcomes of nonsurgical retreatment and endodontic surgery: a systematic review. J Endod. 2009;35(7):930-7.

25.Pagonis TC, Fong CD, Hasselgren G. Retreatment decisions-a comparison between general practitioners and endodontic postgraduates. J Endod. 2000;26(4):240-1.

26. Hommez G, De Moor R, Braem M. Endodontic treatment performed by Flemish dentists. Part 2. Canal filling and decision making for referrals and treatment of apical periodontitis. Int Endod J. 2003;36(5):344-51.

Yazışma Adresi:

Fatma Gülfeşan ÇANAKÇi

Trakya Üniversitesi

Diş Hekimliği Fakültesi

Ağız Diş ve Çene Cerrahisi AD.

Edirne, Türkiye

E Posta: gulfesan@hotmail.com 